\title{
Investigation on 2D Transition Metal Chalcogenide Using Angular-Resolved Photoelectron Spectroscopy
}

\author{
Soohyung Park ${ }^{\dagger}$ \\ Korea Institute of Science and Technology

\section{각도분해 광전자 분광법을 이용한 2차원 전이금속 칼코겐 화합물의 전자구조 연구}

\author{
박수형 † \\ 한국과학기술연구원
}

(Received December 9, 2019; Accepted December 16, 2019)

\begin{abstract}
s
Recently, transition metal dichalcogenide (TMDC) monolayers have been the subject of research exploring the physical phenomenon generated by low dimensionality and high symmetry. One of the keys to understanding new physical observations is the electronic band structure of 2D TMDCs. Angle-resolved photoelectron spectroscopy (ARPES) is, to this point, the best technique for obtaining information on the electronic structure of 2D TMDCs. However, through ARPES research, obtaining the long-range well-ordered single crystal samples always proves a challenging and obstacle presenting issue, which has been limiting towards measuring the electronic band structures of samples. This is particularly true in general 2D TMDCs cases. Here, we introduce the approach, with a mathematical framework, to overcome such ARPES limitations by employing the high level of symmetry of $2 \mathrm{D}$ TMDCs. Their high symmetry enables measurement of the clear and sharp electronic band dispersion, which is dominated by the band dispersion of single-crystal TMDCs along the two high symmetry directions $\Gamma-\mathrm{K}$ and $\Gamma-\mathrm{M}$. In addition, we present two important studies and observations for the direct measuring of the exciton binding energy and charge transfer of 2D TMDCs, both being established by the above novel approach.
\end{abstract}

Key words : Angular-resolved photoelectron spectroscopy, 2D transition metal chalcogenide, Azimuthally disordered system 


\section{1. 머리말}

2차원 전이금속 칼코겐 화합물 (transition metal chalcogenide, TMDC)은 평면방향으로는 강한 공유결합 (Covalent bonding)과 수직방향의 약한 반데르발스결합(van der Waals bonding)의 고유의 원자배열을 가지고 있다. ${ }^{1,2}$ 이 러한 비대칭적 결합구조는 초전도(superconductivity), 전하 밀도파 (Charge density wave), 위상양자상태(topological edge state) $)^{3}$ 와 스핀 홀 효과(spin Hall effect $)^{4,5}$ 와 같은 저차 원과 높은 대칭성에서 기인하는 새로운 물리적으로 현상들을 보여준다. 이러한 물리현상들을 실험적으로 접근하기에 최적 의 방법은 각도분해능 광전자분광법 (Angle-resolved photoelectron spectroscopy, ARPES)이며, 최근 이를 이용 하여 많은 연구들이 보고되고 있다.

\section{2. 각분해능 광전자}

각분해능 광전자분광법은 샘플에 극자외선 또는 X-선 영역의 (10 $1400 \mathrm{eV}$ ) 빛을 조사할 때, 광전효과에 의 해 발생되는 광전자를 측정하는 방법이다. 이때 에너지는 보존되기 때문에 광전자의 에너지를 측정하면 전자가 물 질 내에서 어떠한 에너지로 구속되어 있는지를 알 수 있 다. 운동량 또한 보존되기 때문에 방출된 광전자의 각도 는 전자의 운동량과 비례하게 된다. 즉 전자의 운동에너
지와 방출 각도를 정밀하게 측정할 수 있다면, 전자의 에 너지와 운동량과의 관계, 즉 전자 띠구조 (electronic band structure)를 알 수 있다. ${ }^{6,7}$

$\mathrm{ARPES}$ 측정은 일반적으로 수 $\mathrm{mm}^{2}$ 범위의 충분히 큰 단결정 샘플이 필요하다. 다결정 (poly-crystal) 또는 비 정질 (amorphous) 의 경우 일반적으로 각도 정보가 중 첩되어 운동량 공간 정보가 보존되지 않는다. 따라서 에 너지와 운동량의 분산관계 (전자 띠구조)를 측정하는 것 이 불가능하다. 본 리뷰에서 이야기할 전이금속 칼코겐 화합물은 일반적으로 $100 \mu \mathrm{m}$ 의 미만의 작고 임의의 방 향 $(\varphi)$ 으로 무질서하게 정렬된 단결정이 만들어 진다. ${ }^{8-10}$ 이 크기의 샘플은 특별한 경우를 제외하고는 기존의 $\mathrm{ARPES}$ 측정 및 해석 방법을 통해서는 전자 띠구조를 이 해하는데 제약사항이 많다. 하지만 본 리뷰에서는 2 차원 전이금속 칼코겐 화합물의 저차원과 높은 대칭성을 이용 하여 각분해능 광전자분광측정에 대한 새로운 해석법을 제시하고, 이것을 이용한 측정결과 및 해석들을 소개하고 자 한다.

\section{3. 단층 전이금속 칼교겐 화합물의 높은 대칭성과 전자구조"1}

\section{$\Phi$ - 각도방향으로 중첩된 전자구조의 운동량 공간}

그림 1 (a)와 (b) 는 $\mathrm{D}_{3 \mathrm{~h}}$ 대칭을 가지는 단결정 $\mathrm{TMDC}$

\section{c}

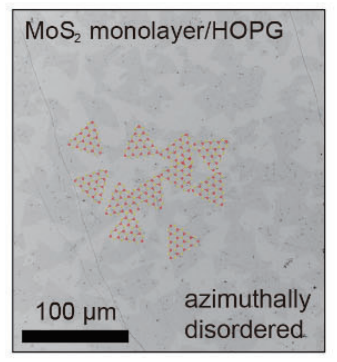

$\mathbf{k}_{\mathbf{x}}\left(\AA^{-1}\right)$

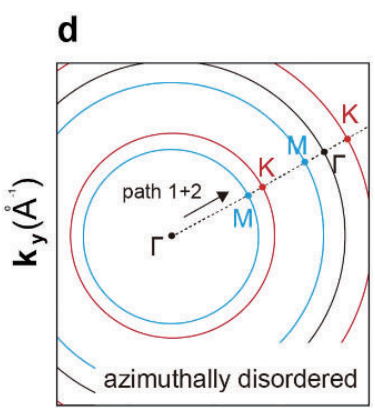

$\mathbf{k}_{\mathbf{x}}\left(\AA^{-1}\right)$

Figure 1. (a) Highly oriented pyrolytic graphite (HOPG) 기판 위의 2차원 전이금속 칼코겐 화합물 (2D-TMDC)의 광학이미지와 원자 배열 모 식도. (b) 단결정 2D-TMDC의 Brillouin zone (BZ)의 모식도와 대칭선과 점 (경로 1: $\Gamma-\mathrm{K}$, 경로 2: $\ulcorner-\mathrm{M}$, 검정 점: $\Gamma$, 적색 점: $\mathrm{K}$, 청 색 점: M). (c) HOPG 기판 위에서 임의의 방향 $(\varphi)$ 으로 무질서하게 분포하는 2D-TMDC의 광학 이미지와 원자배열 모식도. (d) 무 작위적인 방위로 분포하는 2D-TMDC의 BZ 모식도와 대칭 원 (검정선: 「 적색원: $\mathrm{K}$, 청색원: $\mathrm{M})^{11}$ 


\section{특 집 ㅃㅃ 박수형}

의 광학 이미지와 Brillouin zone(BZ)의 모식도 이다. 앞 에서 $\mathrm{ARPES}$ 측정의 검출 영역은 특별한 시스템을 제외 하고 일반적으로 수 $\mathrm{mm}^{2}$ 의 크기를 가진다. 그에 반해 현 재 chemical vapor deposition(CVD), 기계적 박리법 (micromechanical exfoliation) 등으로 만들어진 전형 적인 단층 TMDC 샘플들은 $100 \mu \mathrm{m}$ 의 크기이다. ${ }^{8-10}$ 이 러한 검출 영역과 단결정 샘플의 크기의 차이는, 그림 1(c)에서 볼 수 있듯이, 수많은 임의의 방향 $(\varphi)$ 으로 무질 서하게 배열된 단결정들의 개별적인 중첩을 유도한다. 그 결과, 그림 1 (b)의 개별적인 단결정의 BZ은 그림 $1(\mathrm{~d})$ 와 $\Gamma$ 주위에 원형의 대칭인 BZ으로 재구성되며, 각각 높은 대칭점 $(\mathrm{M}, \mathrm{K}, \Gamma)$ 에 해당하는 반지름을 가진다.

그림 2(a)은 그림 1(c)의 임의의 방향 $(\varphi)$ 으로 무질서하 게 분포하는 단층 $\mathrm{WSe}_{2}$ 의 측정된 $\mathrm{ARPES}$ 스펙트럼이다. 앞에서 언급한 바와 같이, 단결정이 아닌 샘플은 중첩효 과에 의해 $\mathrm{ARPES}$ 스펙트럼에서 에너지 전자 띠구조를 보기 어렵다. 그럼에도 불구하고 그림 2(a) 에서는 매우 선명한 전자 띠구조를 가지는 $\mathrm{ARPES}$ 스펙트럼을 관찰 할 수 있다. 그림 2(a)의 측정된 ARPES 스펙트럼은 그림 2(b)의 계산된 에너지 전자 띠구조와 비교해 보면 거의 완벽하게 일치하는 것을 관찰할 수 있다. 특히 계산된 전 자 띠구조는 2가지 높은 대칭방향만 (경로1: $\Gamma-\mathrm{K}-\mathrm{M}$, 경로2: $\Gamma-\mathrm{M}-\Gamma)$ 을 따라 계산 계산된 결과인데, 이것은 2 차원 $\mathrm{WSe}_{2}$ 의 전자구조 중에서 높은 대칭 방향의 분포가 측정된 $\mathrm{ARPES}$ 스펙트럼에 지배적으로 기여함을 의미한
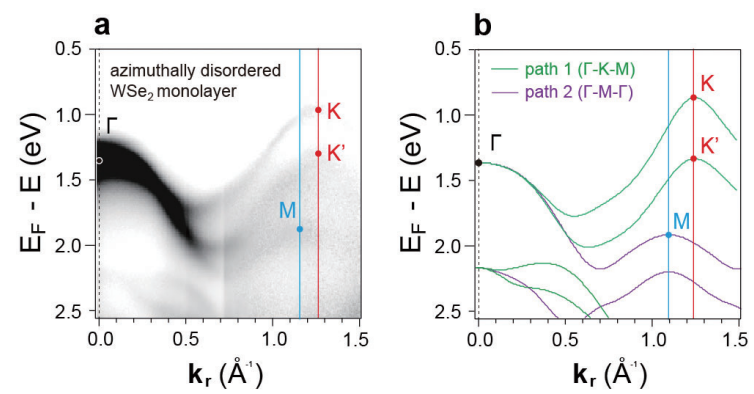

Figure 2. (a) 측정된 무작위적인 방위로 분포하는 단층 $\mathrm{WSe}_{2}$ 의 각 분해능 광전자분광 스펙트럼 (b) 높은 대칭 방향 (경로1: $\Gamma-\mathrm{K}-\mathrm{M}$, 경로2: $\Gamma-\mathrm{M}-\Gamma)$ 를 따라 계산된 2차원 단결정 $\mathrm{WSe}_{2}$ 단층의 전자 띠구조.
다. 또한 측정된 $\mathrm{ARPES}$ 가 운동량 공간에서 오직 반지름 (r)방향의 운동량 $\left(\mathrm{k}_{\mathrm{r}}\right)$ 에만 의존함을 말하고 있다.

\section{ARPES 측정에서 $\Phi$-각도방향의스펙트럼중첩}

광전자분광 실험에서 스펙트럼의 강도(측정된 광전자의 수)는샘플의 면적에 일반적으로 비례한다. 즉, 스펙트럼 의 강도는 특정방향 $(\Phi)$ 을 가지는 단결정의수 $(\mathrm{N})$ 와 이때 개별 단결정에서 방출되는 측정 에너지 $\mathrm{E}\left(\mathrm{k}_{\mathrm{r}}, \varphi\right)$ 와 반지름 방향 운동량 $\left(\mathrm{k}_{\mathrm{r}}\right)$ 의 광전자 분포에 비례한다. 이때 검출영 역내의 임의의 방향을 가지는 $\mathrm{N}$ 이충분히 크다고 가정하 면, 우리는 $\Delta \varphi=2 \pi / \mathrm{N}$ 의 각도 간격 $(\Delta \varphi)$ 하나를 개별 단결 정 하나로 가정할 수 있다. 또한 각 $\Delta \varphi$ 에 대해, $\varphi$ 를 따라 분산되어 있는 해당 절대 에너지 변화량 $|\Delta \mathrm{E}|$ 는 $\mathrm{E}\left(\mathrm{k}_{\mathrm{r}}, \varphi\right)$ 를 $\varphi$ 방향으로 편미분하여 계산할 수 있다. (수식 1)

수식1: $\left|\Delta E\left(\mathbf{k}_{\mathbf{r}}, \varphi\right)\right|=\left|\frac{\partial E\left(\mathbf{k}_{\mathrm{r}}, \varphi\right)}{\partial \varphi} \Delta \varphi\right|=\left|\nabla_{\varphi} E\left(\mathbf{k}_{\mathbf{r}}, \varphi\right) \cdot \mathbf{k}_{\mathbf{r}}\right| \Delta \varphi$

수식 1 을 이용하면, 특정 에너지 간격 $\delta \mathrm{E}$ (예: 실험 에 너지 분해능 $)$ 에 기여하는 $\mathrm{N}\left(\mathrm{E}, \mathrm{k}_{\mathrm{r}}, \varphi\right)$ 을 셀 수 있다.

$$
\text { 수식 2 : } \quad N\left(E, \mathbf{k}_{\mathbf{r}}, \varphi\right)=\frac{\delta E}{\left|\Delta E\left(\mathbf{k}_{\mathbf{r}}, \varphi\right)\right|}=\frac{\delta E}{\Delta \varphi \cdot k_{r}} \frac{1}{\nabla_{\boldsymbol{\varphi}} E\left(\mathbf{k}_{\mathbf{r}}, \varphi\right) \mid}
$$

스펙트럼은 모든 $\varphi$ 방향으로 중첩되어야 함으로, 수식2 는 수식 3 과 같이 다시 정리할 수 있다.

$$
\text { 수식 } 3: I\left(E, \mathbf{k}_{\mathbf{r}}\right) \sim N\left(E, \mathbf{k}_{\mathbf{r}}\right)=\frac{\delta E}{\Delta \varphi \cdot k_{r}} \sum_{\varphi=0}^{2 \pi} \frac{1}{\left|\nabla_{\varphi} E\left(\mathbf{k}_{\mathbf{r}}, \varphi\right)\right|}
$$

정리하면, $\mathrm{ARPES}$ 에서 측정된 스펙트럼의 강도는 $\left|\nabla_{\varphi} E\left(\mathbf{k}_{\mathbf{r}}, \varphi\right)\right|$ 의 역수에 비례한다는 것을 알 수 있다. 주목할 점은 $\left|\nabla_{\varphi} E\left(\mathbf{k}_{\mathrm{r}}, \varphi\right)\right|$ 가 0 에 가까워지는 특정운동량 $\left(\mathrm{k}_{\mathrm{r}}, \varphi\right)$ 지점에서 $I\left(E, \mathbf{k}_{\mathbf{r}}\right)$ 가 발산할 수 있다는 점이며, 이 지점에 서 측정된 $\mathrm{ARPES}$ 스펙트럼의 강도가 매우 큰 값을 가질 것이다. 이것은 특정운동량 $\left(\mathrm{k}_{\mathrm{r}}, \varphi\right)$ 지점에서 동일한 $\mathrm{E}$ $(\mathrm{E} \pm \delta \mathrm{E} / 2$ 범위 내)에 기여하는 단결정의 수 (광전자의 수)가 매우 많다고 물리적으로 해석할 수 있다. 실제 실 험에서는 단위면적당 단결정의 수 $(\mathrm{N})$, 실험의 에너지 분해능 $(\delta E)$ 과 각도 분해능 $(\Delta \varphi)$ 이 유한한 값을 가지 
기 때문에 $I\left(E, \mathbf{k}_{\mathbf{r}}\right)$ 는 무한이 아닌 매우 크지만 유한한 값 을 보여준다.

\section{$\Phi-$ 각도방향의 중첩 스펙트럼의 해석}

측정된 $\mathrm{ARPES}$ 스펙트럼의 물리적 통찰을 얻기 위해, 수식 3 에서 유도한 $1 /\left|\nabla_{\varphi} E\left(\mathbf{k}_{\mathbf{r}}, \varphi\right)\right|$ 와 에너지 전자 띠구조와의 관계를 확인해 보았다. 그림 $3(\mathrm{a})$ 와 $(\mathrm{b})$ 는 단결정 2 차원 단층 $\mathrm{WSe} 2$ 의 계산된 최외곽 에너 지와 $1 /\left|\nabla_{\varphi} E\left(\mathbf{k}_{\mathbf{r}}, \varphi\right)\right|$ 를 운동량 공간에서 그린 지도이다. 그림 3 (c)와 같이 $\varphi$ 방향으로 그림 3 (a)의 최외곽 에 너지 지도를 따라가 보면, 단층 $\mathrm{TMDC}$ 의 $\mathrm{D}_{3 \mathrm{~h}}$ 대칭성 때문에 경로 1 (점선: $\Gamma-\mathrm{K}$ )과 경로 2 (점선: $\Gamma-\mathrm{M}$ ) 를 기준으로 서로 대칭을 이루고 있는 것을 볼 수 있 다. 이것은 경로 1 과 2 를 따라 에너지 구조가 반드시 국소 최대점 또는 최소점이 됨을 의미하여, 이것은 필연적으로 $1 / 1 / \nabla_{\varphi}^{E\left(\mathbf{k}_{\mathbf{r}}, \varphi\right)} \mid$ 의 특이점 (발산)을 야기 시킨 다. 그림 $3(\mathrm{~b})$ 는 대칭선을 따라 $1 / 1 /\left.\right|_{\varphi} ^{E\left(\mathbf{k}_{\mathbf{r}}, \varphi\right) \mid}$ 가 매우 높은 값을 가지고 있는 것을 시각적으로 보여준다. 계산된 그림 $3(\mathrm{~b})$ 의 결과를 가지고 $\mathrm{ARPES}$ 스펙트럼 을 모사하면 그림 $3(\mathrm{~d})$ 와 같다. 그림 $3(\mathrm{~d})$ 대칭선 의 운동량의 선명한 전자 띠구조를 나타내는 스펙트 럼을 볼 수 있다. 이것을 실험 스펙트럼(그림 2 (a)) 과 비교하면 실험과 모델이 매우 일치하는 것을 알 수 있다. 정리하면, 대칭성을 가지는 두 방향만 (경
로 1 과 경로 2$)$ 측정된 $\mathrm{ARPES}$ 의 $I\left(E, \mathbf{k}_{\mathbf{r}}\right)$ 에 대부분 기여한다.

\section{2차원 전이금속 칼코겐 화합물 스펙트럼}

대칭성에서 기인하는 고유의 스펙트럼이 단층 $\mathrm{WSe}_{2}$ 만이 아닌 같은 대칭구조를 가지는 다른 물질에서도 공통 적으로 나타남을 보여주기 위하여, $\mathrm{WSe}_{2}, \mathrm{WS}_{2}, \mathrm{MoSe}_{2}$, $\mathrm{MoS}_{2}$ 와 같이 모두 4 가지 2차원 전이금속 칼코겐 화합물 의 스펙트럼을 측정하였다. 그림 4 에서 보면, 측정된 4 가 지 종류의 스펙트럼과 각각의 계산된 전자 띠구조(경로1 과 경로2)와 겹친 결과가 매우 일치함을 볼 수 있다. 또한 각각의 계산결과와 실험결과는 선행된 단결정 샘플의 결 과와 일치함을 나타낸다. ${ }^{2}$ 추가적으로 각각의 그림 4 의 스펙트럼에서 페르미 준위 $1.70 \AA^{-1}$ (K: 녹색점) 에서 시 작하는 거의 선형의 Highly oriented pyrolytic graphite (HOPG) 기판의 전자 띠구조를 공통적으로 볼 수 있다..$^{13}$

정리하면, $\mathrm{BZ}$ 의 높은 대칭 방향의 $(\Gamma-\mathrm{K}$ 및 $\Gamma-\mathrm{M})$ 전 자 띠구조가 무작위적인 방위로 분포하는 단결정 2 차원 전이금속 칼코겐 화합물의 $\mathrm{ARPES}$ 스펙트럼에 주요하게 기여함을 알 수 있다. 이것은 $\varphi$ 방향 에너지 분산을 특징 으로 하는 전자 띠구조를 단결정 샘플의 크기와 상관없이 측정 가능하게 하며, 이를 이용하여 다른 물리적 특성을 이해하는데 기반이 된다.
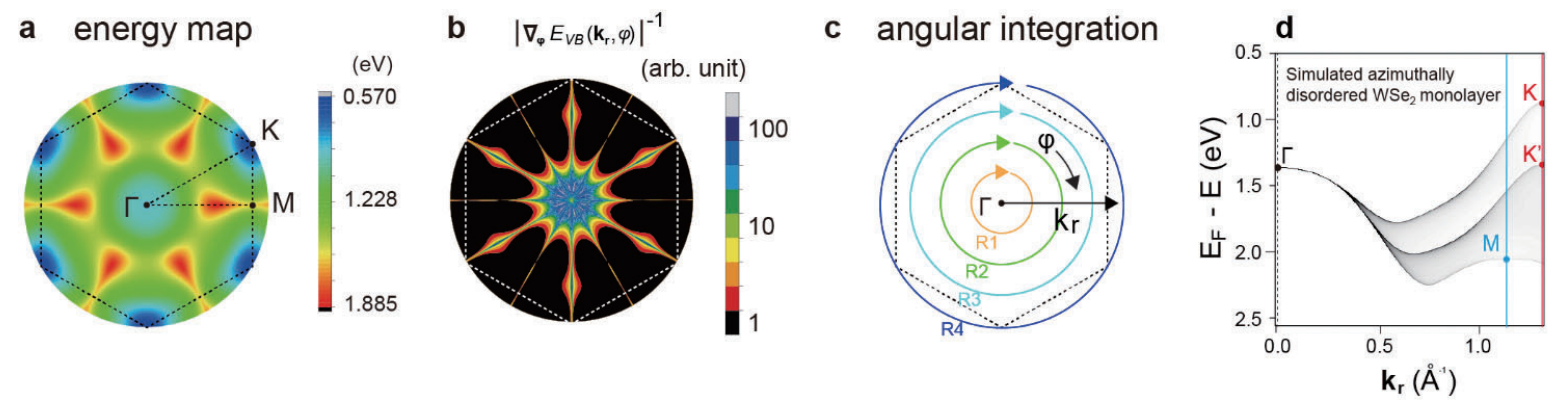

Figure 3. (a) 단결정 2차원 단층 $W \mathrm{Se}_{2}$ 의 계산된 최외곽 에너지를 운동량 공간에서 그린 지도. (b) 에너지 지도로부터 계산된 $\left|\nabla_{\boldsymbol{\varphi}} \boldsymbol{E}\left(\mathbf{k}_{\mathrm{r}}, \boldsymbol{\varphi}\right)\right|^{-\mathbf{1}}$ 값을 운동량 공간에서 그린 지도. (c) 각각의 운동량 값 $\mathrm{K}_{\mathrm{r}}$ (R1부터 R4까지) 에서 $\varphi$ 방향으로 통합을 묘사한 개략도. (d) 수식 3을 통 해 계산된 무작위적인 방위로 분포하는 단층 $\mathrm{WSe}_{2}$ 의 각분해능 광전자분광 스펙트럼. 

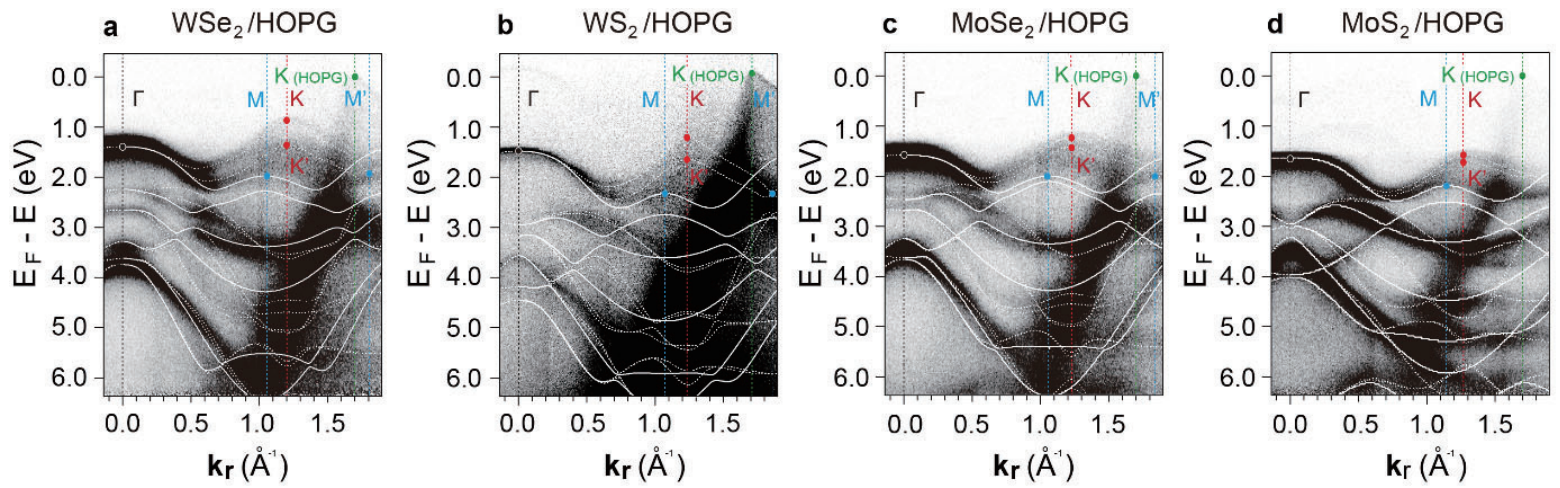

Figure 4. $2 \mathrm{H}-$ 대칭성을 가지는 4가지 2차원 전이금속 칼코겐 화합물 (2D-TMDC)의 각분해 광전자분광 스펙트럼.

\section{4. 대칭성에 기반한 전자구조의 연구결과 소개}

여기에서는 앞에서 언급한 대칭성에서 기인하는 전자 구조를 이용하여 관측한 물리적 현상의 예를 2 가지를 소 개하고자 한다.

\section{$\mathrm{MoS}_{2}$ 단층의 엑시톤 바인딩 에너지 ${ }^{14}$}

2차원 전이금속 칼코겐 화합물의 광학적 특성을 이해 하는데 있어서 엑시톤(exciton)에 대한 정보는 매우 핵심 적이다. 엑시톤이란 빛에 의해 생성된 홀과 전자가 다시 정전기력(Coulombic force)에 의해 결합된 준입자상태 (quasi-particle)를 의미한다. ${ }^{15-17}$ 엑시톤은 물질에 따라
서로 다른 결합에너지를 가지고 있는데 이를 엑시톤 바인 딩 에너지 (exciton binding energy) 라고 하며, 이 에너 지의 크기에 따라 빛에 의한 물질의 전기적 특성이 매우 달라진다. 즉 정확한 엑시톤 바인딩 에너지를 직접적으로 측정하는 것 필요하다. 정확한 엑시톤의 바인딩 에너지는 광학적 흡수를 통해 얻을 수 있는 광학갭(Optical band $\mathrm{gap}$ 과 각도분해능 광전자/역광전자분광법을 이용한 전 기갭 (electrical band gap)의 차이로 측정할 수 있다. 앞 에서 언급한 대칭성을 이용하면 지금까지 측정/해석하기 어려웠던 2 차원 전이금속 칼코겐 화합물의 전기갭을 측 정 가능하게 한다. 그림 5 는 대표적인 2차원 전이금속 칼 코겐 화합물의 $\mathrm{MoS}_{2}$ 의 엑시톤 바인딩 에너지를 측정한

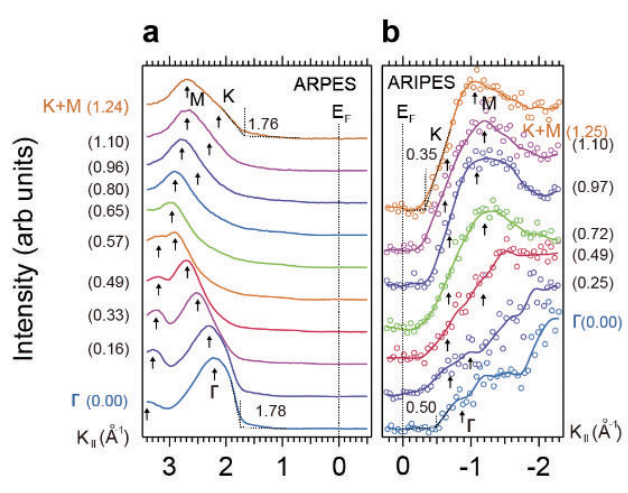

Binding energy with respect to Fermi level (eV)

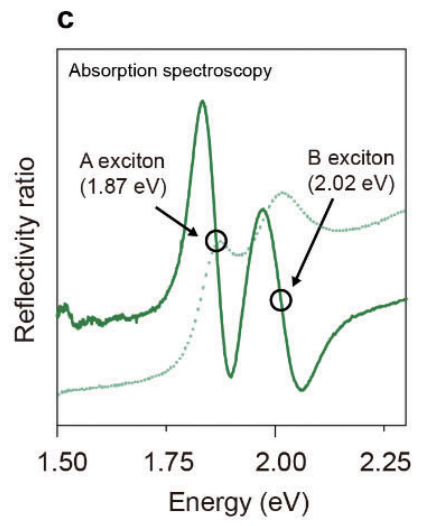

d

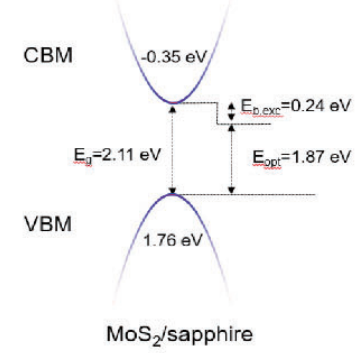

Figure 5. 2차원 단층 $\mathrm{MoS}_{2}$ 의 (a) 각분해능 광전자분광과 (b) 역광전자분광 스펙트럼. 2차원 단층 $\mathrm{MoS}_{2}$ 의 (c) 반사 스펙트럼과 (c) 1차 미분 스펙트럼. (d) 측정된 2차원 단층 $\mathrm{MoS}_{2}$ 의 에너지 레벨 모식도와 엑시톤 에너지.14 
선행 보고이다. ${ }^{14}$ 단층 $\mathrm{MoS}_{2}$ 의 각분해능 광전자/역광전 자 스펙트럼을 통해 $\mathrm{K}$ 지점에서 $2.11 \mathrm{eV}$ 의 전기갭을 측 정할 수 있다. 정리하면 전기갭과 광학갭을 각각 측정하 여 $0.24 \mathrm{eV}(2.11-1.87)$ 의 엑시톤 바인딩 에너지는 정밀 하게 측정하였고 이를 통해 $\mathrm{MoS}_{2}$ 의 전기/광학적 특성을 정량화 할 수 있었다.

\section{$\mathrm{MoS}_{2}$ 의 유기분자 도핑 18}

2차원 전이금속 칼코겐 화합물의 에너지 레벨의 조절 은 소자의 성능을 최적화 하는데 필수적인 요소이다. 에 너지 레벨 조절을 위하여 많은 접근법들이 제안되어왔는 데, 그 중 유기분자의 표면 도핑을 통해 전하전도를 유도 하는 방법이 제안되었다. ${ }^{19-22}$ 일반적으로 유기분자의 표 면 도핑은 필연적으로 무질서한 공간분포를 유도한다. 이 것은 일반적으로 $\mathrm{ARPES}$ 를 이용한 전자 띠구조 측정을 어렵게 한다. 따라서, 얼마나 많은 전하가 어떤 방식으로 도핑을 유도하는지 직접적으로 알기 어려웠다. 하지만 2 차원 전이금속 칼코겐 화합물의 경우 대칭성에서 기인하 는 전자구조를 이용하면 아주 얇은 영역에서 대칭성을 유 지시켜 $\mathrm{ARPES}$ 를 이용한 분석을 가능하게 해준다.

그림 6에서 볼 수 있듯이 무질서하게 정렬한 단층 $\mathrm{MoS}_{2}$ 의 전자 띠구조가 대칭성 때문에 선명하게 측정됨 을 알 수 있다. 이를 통해 높은 두 대칭성방향 $(\Gamma, \mathrm{K})$ 의 정보를 동시에 측정이 가능했다. $\mathrm{P}$-도핑 성질을 가지는 유기분자 $\quad 1,3,4,5,7,8$-hexafluoro-tetracyan onaphthoquinodimethane ( $\left.\mathrm{F}_{6} \mathrm{TCNNQ}\right)$ 를 $5 \AA$ 수준으로 매우 얇게 증착 하는 경우 단층 $\mathrm{MoS}_{2}$ 의 대칭성이 유기분 자와 기판의 상호작용 때문에 붕괴되지 않는다. 이것은 그림 6의 $\mathrm{ARPES}$ 스펙트럼이 여전히 대칭성에 의해 전자 띠구조를 유지하는 것을 통해 유추할 수 있다. 정리하면 대칭성의 기반한 $\mathrm{ARPES}$ 스펙트럼 해석과 그 변화량을 기반으로 유기분자가 2차원 전이금속 칼코겐 화합물의 전자변화를 측정하였고, 전하교환 양을 정량화 할 수 있 었다.

\section{5. 맺음말}

2차원 전이금속 칼코겐 화합물의 높은 대칭성에서 기 여하는 전자구조는 단결정 샘플의 크기와 정렬에 상관없 이 ARPES 측정 가능하며, 이것은 BZ의 2 개의 높은 대 칭 방향의 $(\Gamma-\mathrm{K}$ 및 $\Gamma-\mathrm{M})$ 전자 띠구조가 주요함을 확 인하였다. 여기에서 리뷰된 측정/분석법을 활용하여 2차 원 전이금속 칼코겐 화합물의 엑시톤 바인딩에너지, 유기 분자 계면에서의 전하전도 등 물리적 특성을 연구한 몇 가지 예를 살펴보았다. 대칭성에 기반한 전자구조 분석법 은 단지 2차원 전이금속 칼코겐 화합물 외에도 높은 대칭 성을 가지는 물질계의 전자구조를 측정하는데 있어 매우 유용한 방법으로 사용 가능할 것이다. 이러한 접근법을 활용하여 앞으로 더욱 의미 있는 연구결과가 발표되기를 기대한다.

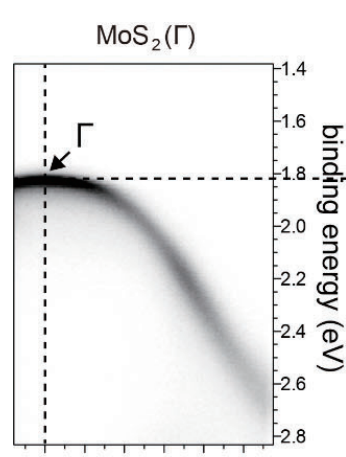

$\mathrm{k}_{\mathrm{r}}\left(\AA^{\prime}\right)$

\section{$\mathrm{F}_{6} \mathrm{TCNNQ} / \mathrm{MoS}_{2}(\Gamma)$}

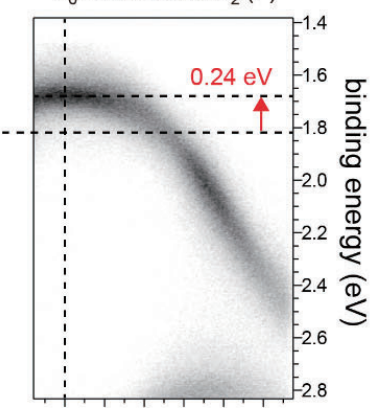

$\mathrm{k}_{\mathrm{r}}\left(\AA^{\prime}\right)$

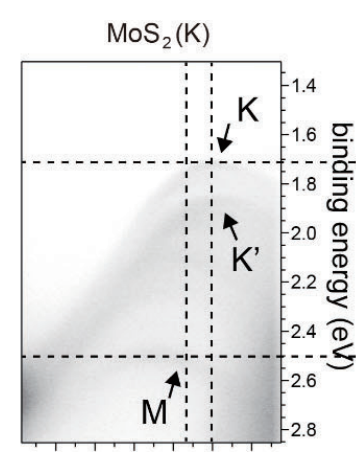

$\mathrm{k}_{\mathrm{r}}\left(\AA^{\prime}\right)$

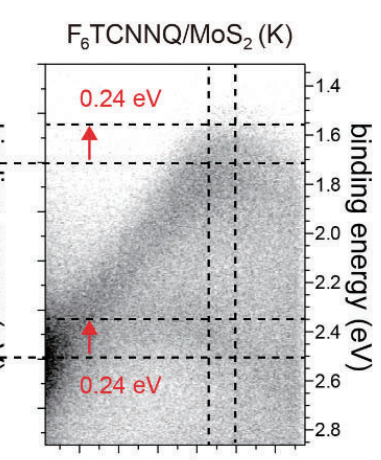

$\mathrm{k}_{\mathrm{r}}\left(\mathrm{A}^{\prime}\right)$

Figure 6. 측정된 단층 $\mathrm{MoS}_{2}$ 의 ARPES 스펙트럼 (왼쪽부터: $\mathrm{MOS}_{2} / \mathrm{HOPG}$ ( $\left\ulcorner\right.$ 지점), $\mathrm{F}_{6} \mathrm{TCNNQ}(5 \AA)$ /단층 $\mathrm{MoS}_{2} / \mathrm{HOPG}$ ( $\ulcorner$ 지점), $\mathrm{MOS} / 2 / \mathrm{HOPG}$ (K지점), $\mathrm{F}_{6} \mathrm{TCNNQ}(5 \AA) /$ 단층 $\mathrm{MoS}_{2} / \mathrm{HOPG}\left(\mathrm{K}\right.$ 지점)). ${ }^{18}$ 


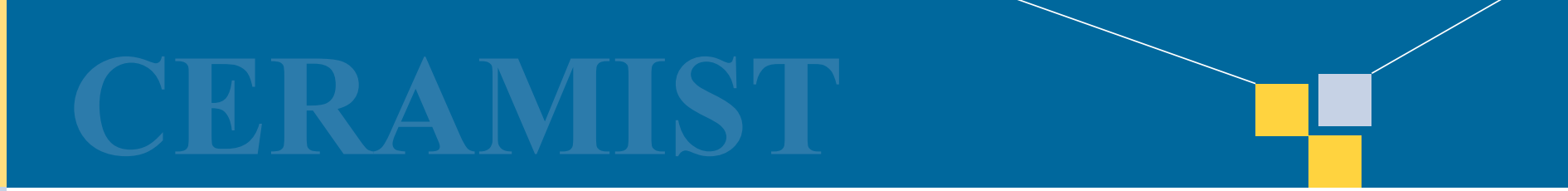

\section{참고문헌}

1. Ye, M., Winslow, D., Zhang, D., Pandey, R. \& Yap, Y. Recent Advancement on the Optical Properties of Two-Dimensional Molybdenum Disulfide $\left(\mathrm{MoS}_{2}\right)$ Thin Films. Photonics 2, 288 - 307 (2015).

2. Chhowalla, M. et al. The chemistry of two-dimensional layered transition metal dichalcogenide nanosheets. Nat. Chem. 5, 263-275 (2013).

3. Gmitra, M., Kochan, D., Högl, P. \& Fabian, J. Trivial and inverted Dirac bands and the emergence of quantum spin Hall states in graphene on transition-metal dichalcogenides. Phys. Rev. B 93, 155104 (2016).

4. Savero Torres, W. et al. Spin precession and spin Hall effect in monolayer graphene/Pt nanostructures. $2 D$ Mater. 4, 041008 (2017).

5. Avsar, A. et al. Spin-orbit proximity effect in graphene. Nat. Commun. 5, 4875 (2014).

6. Ashcroft, N. W. \& Mermin, N. D. Solid State Physics. in Solid State Physics iii (Elsevier, 1976).

7. Stefan Hüfner. Photoelectron Spectroscopy: Principles and Applications. (Springer, 1995).

8. Ly, T. H. et al. Observing Grain Boundaries in CVDGrown Monolayer Transition Metal Dichalcogenides. ACS Nano 8, 11401-11408 (2014).

9. Zhou, J. et al. A library of atomically thin metal chalcogenides. Nature 556, $355-359$ (2018).

10. Li, B. etal. Solid-Vapor Reaction Growth of TransitionMetal Dichalcogenide Monolayers. Angew. Chemie Int. Ed. 55, 10656 - 10661 (2016).

11. Park, S. et al. Electronic band dispersion determination in azimuthally disordered transition-metal dichalcogenide monolayers. Commun. Phys. 2, 68 (2019).

12. Ramasubramaniam, A. Large excitonic effects in monolayers of molybdenum and tungsten dichalcogenides. Phys, Rev. B 86, 115409 (2012).

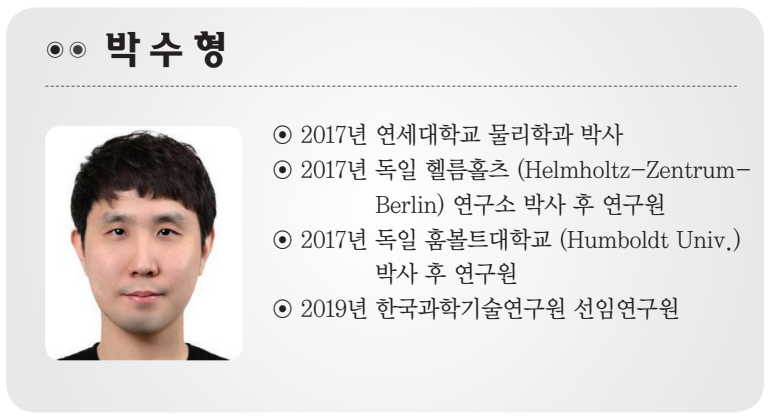

13. Zhou, S. Y. et al. Coexistence of sharp quasiparticle dispersions and disorder features in graphite. Phys. Rev. B 71, 161403 (2005).

14. Park, S. et al. Direct determination of monolayer $\mathrm{MoS}_{2}$ and $\mathrm{WSe}_{2}$ exciton binding energies on insulating and metallic substrates. 2D Mater. 5, 025003 (2018).

15. Zhu, B., Chen, X. \& Cui, X. Exciton Binding Energy of Monolayer $\mathrm{WS}_{2}$. Sci. Rep. 5, 9218 (2015).

16. Chernikov, A. et al. Electrical Tuning of Exciton Binding Energies in Monolayer $\mathrm{WS}_{2}$ Phys. Rev. Lett. 115, 126802 (2015).

17. Palummo, M., Bernardi, M. \& Grossman, J. C. Exciton radiative lifetimes in two-dimensional transition metal dichalcogenides. Nano Lett. 15, 27942800 (2015).

18. Park, S. et al. Demonstration of the key substratedependent charge transfer mechanisms between monolayer MoS2 and molecular dopants. Commun. Phys. 2, 109 (2019).

19. Cheng, Y. C., Zhu, Z. Y., Mi, W. B., Guo, Z. B. \& Schwingenschlögl, U. Prediction of two-dimensional diluted magnetic semiconductors: Doped monolayer $\mathrm{MoS}_{2}$ systems. Phys. Rev. B 87, 100401 (2013).

20. Rastogi, P., Kumar, S., Bhowmick, S., Agarwal, A. \& Chauhan, Y. S. Doping Strategies for Monolayer $\mathrm{MoS}_{2}$ via Surface Adsorption: A Systematic Study. J. Phys. Chem. C118, 30309 - 30314 (2014).

21. Dolui, K., Rungger, I., Das Pemmaraju, C. \& Sanvito, S. Possible doping strategies for $\mathrm{MoS}_{2}$ monolayers: An ab initio study. Phys. Rev. B 88, 075420 (2013).

22. Du, Y., Liu, H., Neal, A. T., Si, M. \& Ye, P. D. Molecular doping of multilayer $\mathrm{Mos}_{2}$ field-effect transistors: Reduction in sheet and contact resistances. IEEE Electron Device Lett. 34, 1328-1330 (2013). 